\title{
AESTHETIC INTELLIGENCE AND AESTHETIC EXPERIENCE IN CHILDREN
}

\author{
Lilly K V and Sudhakar Venukapalli
}

The English and Foreign Languages University, India

\begin{abstract}
How do children experience music, art, emotions, and beauty? Is aesthetic potential in children innate or acquired? Do children understand the world around aesthetically? Is aesthetic experience a developmental process? How can teachers provide students with opportunities to experience aesthetics for cognitive, social, cultural, and psychological development? These are some of the fascinating questions in the field of contemporary aesthetic education. This paper presents what is aesthetic experience and how it enriches the lives of children. Children should be exposed to fine arts and support from teachers will help them to find meaning in fine arts. Visual arts curriculum will help children in cognitive development by continuously constructing new knowledge and integrating it into existing knowledge. Curriculum designed to teach aesthetic experience should incorporate both art viewing and art making. Aesthetic experience integrates mind, body, and emotion. It can induce personal growth in children, and it is intrinsically satisfying.
\end{abstract}

\section{KEYWORDS}

Aesthetic experience, Cognition, Aesthetic intelligence, Aesthetic Judgement, Aesthetic learning

\section{INTRODUCTION}

How do children experience music, art, emotions, and beauty? Is aesthetic potential in children innate or acquired? Do children understand the world around aesthetically? Is aesthetic experience a developmental process? How can teachers provide students with opportunities to experience aesthetics for cognitive, social, cultural, and psychological development? These are some of the fascinating questions in the field of contemporary aesthetic education. This paper explores what is aesthetic experience and the possibilities of aesthetic learning in children. Various components of aesthetic experiences namely, context, content, style, knowledge, expertise, and emotion are elaborated. The paper also presents three important characteristics of aesthetic experience: the motivational, oriental, or attentive aspects of aesthetic experience, the cognitive aspect of aesthetic experience, and the affect aspect of aesthetic experience. Different aspects of aesthetic understanding of children and how a curriculum enriched with aesthetic experience will augment the learning environment of children are explained.

What is Aesthetic Experience? The word "aesthetic" is designated as the experience of beauty. The German philosopher Baumgarten (1714-1762) first introduced the term "aesthetics" to refer to the realm of art and beauty. He considered beauty and art within the realm of feelings and not in intellect. The experiencing of something as beautiful is part of human activity. The level of aesthetic experience is characterised by liberation, ecstasy, or pleasure, and it is the same level on which the artist expresses his experiences and upon which the viewer experiences the work of art.

In her acclaimed work on Aesthetic Intelligence, Pauline Brown (2019) contends that "aesthetics is the pleasure that human beings could elicit from perceiving an object or which can be 
experienced through our senses. On the other hand, aesthetic intelligence is regarded as our capability to comprehend, interpret, and articulate feelings that are derived by a particular object or experience."

Aesthetic experience is one of the vaguely defined concepts in the psychology of art. Generally, "aesthetic experience is defined as a particular state of mind that differs qualitatively from the aesthetic preference and judgement of beauty which is a domain of everyday experience" (Markovic, 2012). Cupchik \& Winston (1996) explained aesthetic experience as a specific "psychological process where the attention is directed on the object whereas all other objects, events, and everyday concerns are suppressed." According to Ognjenovic (1997), "aesthetic experience is regarded as a particular kind of subject-object relationship in which a certain object powerfully engages the subject's mind, thus shadowing all other surrounding objects and events" (cited in Markovic, 2012). Apter (1984) suggests that the "distinctive feature of aesthetic experience is that it is not goal directed (i.e., pragmatic), but focused more upon the activity itself (i.e., self-rewarding)."

For many years, aestheticians believed that aesthetic experience could be the result of engagement with any objects, situations, natural environment, and the like. Some argued that aesthetic experience can be best obtained by viewing works of art. They reckon that artworks provide aesthetic experience to the fullest because their configuration advances aesthetic experience. In this article we take the stand with Ralph Smith (1986/87) who argued that for achieving aesthetic experience, the best possible way is to engage with outstanding works of art. Ralph Smith's concept of artworks concurs with the idea of Goodman (1984). He argues that artworks are ideal "when by stimulating inquisitive looking, raising visual intelligence, widening perspectives, bringing out new connections and contrasts, and marking off neglected significant kinds, they engage in the organization and reorganization of experience" (cited in Parsons, 2002).

Csikszentmihalyi (2000) argued that "the aesthetic experience is a species of the genus optimal experience". A viewer feels an aesthetic experience while viewing an artwork will be fully immersed in the artwork and is unmindful of the external happenings. This is referred to as "the magic we see in art" and is not associated with any external rewards. Csikszentmihalyi contends that achieving this requires practice. Appreciation of natural beauty also evokes aesthetic experience, but it differs from the experience we obtain through artworks because artworks are "metaphorical and culturally embedded."

Ralph Smith (1991) propose five norms for an aesthetic experience: “(1) object directedness and concentrated attention; (2) felt freedom or the release from the dominance of antecedent concerns; (3) detached affect that permits reflection, empathy, and insight into one's own and others' feelings and emotions; (4) cognitive processes of active discovery; and (5) wholeness or a sense of integration which involves coherence of feelings, ideas, and perceptions. Contentment is a typical and positive result of the sense of wholeness".

Considering Csikszentmihalyi's idea of optimal experience and Smith's notion of aesthetic experience, Lankford (2002) identifies the following benefits of aesthetic experience. He contends that aesthetic experience leads to the development of "cognitive, affective, perceptual, sensory, and empathetic aptitudes". This will be advantageous for individuals as well as for the society. Further he suggests that this experience varies among individuals depending on their abilities and socio-cultural and environmental factors. 


\section{Cognitive Psychology of Aesthetic Experience}

Sensory engagement is usually related to aesthetic experience but whether aesthetics is cognitive as well as sensory has baffled psychologists and philosophers for centuries. Though it was discussed from the time of Plato, Baumgarten who coined the term "aesthetics" contended that engagement in aesthetic activity (or in other terms the aesthetic experience) leads to cognition because "much could be learned through sensory perception" (Black, 2000). The study of the psychology of art incorporates various methods including experimental studies, cognitivebehavioural studies as well as psychophysiology and brain research. Psychological approaches to art suggest that aesthetic experiences of art involve a complex interplay of interaction of "cognitive and emotional processes" (Cupchik et al., 2009; Leder et al., 2004; Vartanian \& Nadal, 2007).

The empirical study of the psychology of art faces various problems. One of the problems faced by them is that according to psychologists, most of the cognitive and emotional processes are not directly observable and they take place in an extremely fast succession. These processes are not directly accessible to consciousness and are difficult to report. In experimental aesthetics, behavioural measurements are generally used as dependent variables. In behavioural measurements, aesthetic evaluations are often measured by preference decisions. On the other hand, psychophysiology uses different methods for testing hypotheses associated with physiological correlates. These methods include electroencephalography, EEG; magnetoencephalography, MEG; electrodermal activity, EDA; heart rate, HR; facial electromyography, facial EMG; and pupillometry. During the last decade, brain activity underlying aesthetic experience was examined using methods such as EEG, MEG and functional magnetic resonance imaging, fMRI (Leder, Gerger, \& Brieber, 2015).

Various neuroimaging studies have been carried out to identify distinct cortical areas which are activated during aesthetic experience of paintings. Studies using functional magnetic resonance imaging (fMRI) (Jacobsen et al., 2006; Kawabata \& Zeki 2004; Vartanian \& Goel 2004) found that "evaluating a stimulus as beautiful was associated with increased activation in the orbital frontal cortex." Cela-Conde et al. (2004) examined brain activity of viewers during aesthetic experience of artworks using magnetoencephalography (MEG) and found that activity in the dorsolateral prefrontal cortex is activated during the cognitive mastering and evaluation stage in the aesthetic experiences framework proposed by Leder et al. (2004). Aesthetic experience involves perception, cognition, imagination, emotion, and discovery.

Perception: when we engage with the formal qualities of an artwork, we experience the artwork, and these formal qualities can affect us. While we perceive an artwork, we identify the elements constituting the artwork including colour, composition, lines and obtain a better understanding of the artwork. Perception is a significant component of aesthetic experience because understanding and reflecting on the formal elements of art results in comprehending the artwork.

Cognition is involved when we understand that a work of art is man-made, and it can be differentiated from natural objects. The artist uses symbols to convey meanings and these symbols are cognitive in nature. Cognition also pertains to our understanding of the content and context of the artwork. The cognitive aspect of aesthetic experience is also significant as it helps the perceiver to acquire language in order to articulate the subjective effect of the artwork.

Imagination helps us to recall our past experiences and relate it with the current stimuli. It also refers to our capacity to contemplate the artwork beyond what we see or portrayed in the artwork. In reference to aesthetic experience, imagination is the unleashing of thoughts while viewing an 
artwork which helps in recollecting past experiences. Imagination is important as it enable us to communicate with the artist. This imagination directs us to new ways of feeling and thinking which will stimulates our emotions. "Imagination deepens aesthetic understanding because when we allow ourselves to look beyond surface and free ourselves to look at the world creatively, we engage in a thought process similar to that of the artist" (Black, 2000).

Emotion: refers to the emotional state of the artist while creating the artwork and the emotional state of the viewer after viewing an artwork. It includes positive emotions like love or inspiration and negative emotions like frustration or disgust. An emotional response is also a form of cognition. An emotional response may evoke nostalgia, takes us back to past experiences and it also affect the way we interpret the artwork.

Discovery: it can be formal or personal; formal discovery happens when we discover new elements in finding meaning to the whole artwork and personal discovery occurs when we discover something about ourselves and the world while viewing the artwork.

Eisner (2002) also argues that aesthetic experience fosters cognition. He proposes six ways through which arts can attain this: "(a) The arts make us think. Thinking is cognitive; (b) the arts makes us observe the world more deeply; (c) the arts provide us permission to engage in imagination for new possibilities; (d) the arts have a high threshold for ambiguity, uncertainty, and exercise of judgement, free from rules; (e) the arts provide a method for inscribing a semipermanent place for ideas; and (f) the arts allow us to explore our interior landscapes, our intrapersonal spaces" (pp 9-11).

\section{Characteristics of Aesthetic EXPERIEnCE}

Aesthetic experience is similar to Csikszentmihalyi's (1975) concept of flow. Csikszentmihalyi defined flow as an "effortless mental energy flow produced by the awareness of congruence between incoming information and our goals. It is a particular state of mind where people are deeply engrossed in their activities, with intense engagement in the process of the activity" (Csikszentmihalyi, 1975). Aesthetic experience is also associated to Maslow's concept of "peak experience" (Maslow, 1968). He exhorts that in peak experiences "attention is entirely focused and directed on a particular object, while the object is found as separated from its routine purpose and usefulness." (1968). Markovic (2012) argues that "aesthetic experience is similar to the component arousal, which means the interest for the paintings: when the individual experiences a greater arousal, his aesthetic fascination would be the highest".

Aesthetic experience is likened to the concept of "absorption" as suggested by Tellegan \& Atkinson (1974). They argued that absorption is the "characteristic of having experiences of increased attention where the subject's mental (perceptual, representational) and executive (motor) resources are fully involved".

Recent notion of aesthetic experience regards it as a psychological process in which attention is focused on the object and everyday concerns is suppressed (Cupchik \& Winston, 1996). Anthony, Earl of Shaftesbury (1711/1964), a British philosopher of Enlightenment, "juxtaposed a 'disinterested' enjoyment of something for its own sake and 'interested' enjoyment of anticipated benefits." His student, Frances Hutcheson (1725), argued that a special "taste" faculty is involved during the experience of beauty, which is a measure of beauty resulting in disinterested pleasure. Kant (1790/1914) too agreed with the concept of "disinterested satisfaction" but rejected the idea of separate faculty of taste. He argued that "the cognitive faculties that are engaged in the experience of ordinary objects and those that provide pleasure by experiencing beauty are the 
same". Schopenhauer (1818/1969) explained the concepts proposed by Kant and suggested that "everyday consciousness is in the service of the will; a state of disinterested detachment can be achieved in which qualities can be suitably contemplated." Beardsley (1958/66) contends that aesthetic experience is a definite process. He argued that "aesthetic experience involves affect that is slightly detached and a sense of freedom from concerns about past and future" (cited in Cupchik et al., 2009). The current psychological aesthetics encompass the concepts evolved through Shaftesbury, Hutcheson, Kant, Schopenhauer, and Beardsley. Modern aestheticians propose aesthetic experience as a distinct experience where pleasure is caused by the "disinterested deliberation of objects."

Cupchik et al. (2009) investigated how cognitive control and perceptual facilitation can influence aesthetic perception and aesthetic emotion. He used fMRI to study aesthetic perception and aesthetic emotion. The results of the study showed that aesthetic experience is a result of the "interaction between top-down orienting of attention and bottom-up perceptual input" (2009).

Markovic (2012) proposed three distinct characteristics of aesthetic experience:

(i) "The motivational, oriental or attentive aspect of aesthetic experience". Here, the individuals experience a state of deep attention and extreme watchfulness. Their attention is focused, and they are absorbed with the specific object.

(ii) "The cognitive, i.e., semantic, symbolic, and imaginative aspect of aesthetic experience". In this cognitive aspect, the individual examines the aesthetic objects and events as elements of a symbolic or 'virtual' reality and transcends their daily uses and meanings.

(iii) The affective aspect of aesthetic experience which refers to the exceptional emotional experience.

Parsons (2002) argues that an experience becomes an aesthetic experience when it possesses certain characteristics. One of the major characteristics is that the experience should be "object centred" which means that the experience focuses on the features of some object other than the self. In other words, aesthetic experience is comprehending the aesthetic qualities of the object. Some of the other characteristics of aesthetic experience encompasses "a sense of heightened awareness and of control" which helps us to reflect on the qualities of the object. It also involves a deeper engagement with the object. Aesthetic experience also includes a "sense of freedom" which is a liberation from the self and understanding of the world. This is significant as it leads us to the contemporary notion that aesthetic experience is cognitive because it involves intense attention, investigation and comprehending the qualities of objects which are all aspects of cognition.

\section{COMPONENTS OF AESTHETIC EXPERIENCES OF ART}

Leder, Gerger, \& Brieber (2015) identified various components in the aesthetic processing of art. It includes context, early perceptual processes such as style or content, knowledge, expertise, and emotion.

(a) context - an aesthetic context encourages the perceiver to adopt an aesthetic attitude (Cupchik \& Laszlo, 1992). Leder et al. (2004) argues that aesthetic context might lead to aesthetically pleasing and cognitively challenging experiences when looking at art. 
(b) aesthetic emotions - aesthetic emotions are produced by intrinsic appraisal of the aesthetic qualities of the object. Studies are conducted to distinguish the emotions produced by art and everyday emotions. Scherer (2005) suggests that aesthetic emotions lack the immediacy of adapting to current events. An aesthetic context enables a more positive perception of a negatively valenced stimuli, especially artworks. At the same time, the context does not erase negative reactions to emotionally negative stimuli. Thus, the positive and negative aspects of emotional experience are differentially affected by an aesthetic context.

(c) early perceptual processes - (a) representations: content and style - Kuchinke and colleagues (2009) found that during the processing of an artwork, content recognition was accompanied by an emotional response and style follows content (Augustine et al., 2011 cited in Leder et al., 2015). (b) art expertise and knowledge - the increased ability to interpret art facilitates understanding and art appreciation.

Swami (2013) argued that increased understanding of artwork mediates the positive effect of additional information on art appreciation. However, the impact of additional information on art appreciation depends on the level of expertise. In conclusion, Leder and colleagues (2015) argued that knowledge, a core feature of art expertise facilitate independent aesthetic judgements and enable the subjects to master viewing artworks more extensively on higher order cognitive level.

\section{Aesthetic Understanding OF ChILdRen}

Feldman (1994) proposes that an "an individual's development in art is non-universal." On the other hand, various aspects including cultural, social, and educational aspects influence an individual's development in art. For centuries arts have become an essential component of our everyday life. It was believed to have enhanced humanity. A person's contextual knowledge and his/her skill at discrimination allows them to associate with a work of art (Chen, 2001). To appreciate aesthetic objects, a viewer must possess the capacity to identify pertinent qualities in those objects.

Danko-McGhee (2006) argues that young children can have aesthetic experience. When children articulate their preferences for colours, shapes, and tastes, they are making their aesthetic preferences. This helps them to develop their own styles to engage with the world. This shapes their aesthetic experiences. "Children require exposure to fine arts for their aesthetic development and as they grow older, they should get opportunities to discuss art and beauty with adults" (Schirrmacher, 2002 cited in Danko-McGhee, 2006). Adults can lead children by helping them find out different aspects to be searched in the beauty of an object. Interesting artworks should be introduced to children to achieve this goal.

Children engage with art in different places and in a variety of contexts. But how can it develop their aesthetic understanding? Heid (2008) shares three principles to achieve such a learning environment: "teaching students to care, providing opportunities for socio-cultural practice, and enriching the curriculum with aesthetic experiences." She further contends that learning happens best in an "atmosphere of care" and it fosters "socio-cultural relationships", and it might lead to aesthetic experiences.

\section{AESTHETIC EXPERIENCES IN CHILDREN'S LEARNING}

"The aesthetic process involves active engagement rather than passive taking in" (Schirrmacher, 2002 cited in Danko-McGhee, 2006). While appreciating artworks children develop perceptual 
abilities. "Children's perception can be improved by engaging them to look at art, reflect upon it, create art, and experience art. True perception requires thought" (Eglinton, 2003). This aesthetic process requires "critical thinking", and adults should help children to develop this ability. During this process children may bring in their past life experiences which will foster making meaning of an artwork. When we organize teaching and learning situations, aesthetic sensitivity of children should be taken care for optimum learning.

Aesthetic experience is a result of contemplation of a work of art. An artwork is created by an artist who not only elicits ideas from the artistic traditions, socio-cultural and historical context, but also include her own personal feelings and thoughts. People who are acquainted in artistic traditions and socio-cultural and historic context and can empathise with human experiences can find meaning while engaging with artworks and attain flow experiences (Lankford, 2002). Though some are born with the capacity to contemplate, children must develop that skill and it requires sharpening of that skill over a period of time. Children need guidance from teachers or art educators to engage with a work of art. Aesthetic experience is pivotal to the meanings constructed while engaging with works of art and it has a deeper impact on the life of an individual.

To enhance aesthetic experiences in children, children should have opportunities for developmentally appropriate ways of engaging with works of art. It can be "play, conversations, and authenticating the experience" (Cole, 1994). Play using tangible objects helps to make connections between the child and the artwork. Conversation is directed towards the language development while talking about the artwork. Authenticating the experience directs the children to associated studio activities (Danko-McGhee, 2006).

Savva (2003) argues that "children should construct their own meanings and understandings about an artwork rather than being provided with factual information. Savva \& Trimis (2005) suggests that looking at art is a skill, and this skill can be developed by conscious effort over the years. Therefore, if visits to museums or any cultural places are designed as developmentally appropriate, it may enhance the aesthetic experiences of children (Danko-McGhee, 2006).

Today we experience visual arts while we travel, watch videos, watch TV programmes, searching a web and a number of similar activities. During 18th century, when theories were proposed on arts and beauty, philosophers termed it as "disinterested" and it is rightly believed that this is the forerunner of 20th century aesthetic experience. It is so because this experience is of intrinsic value not for any practical or social value. And fine arts are considered as providing this sort of experience more than any other objects.

\section{CONClusions}

Popular culture are that which are easily accessible by means of our family or society which are aesthetically familiar whereas fine arts are less accessible and are claimed to arouse perceptual attention. It therefore warrants that children should be exposed to fine arts and they may be provided with support from teachers to find meaning in fine arts. A visual arts curriculum will help children in cognitive development by continuously constructing new knowledge and integrating it into existing knowledge. If we aim at intensifying the cognitive ability of students, curriculum must include both popular arts and fine arts of varying levels of complexity. Our children should be provided with opportunities to explore visual cultures to educate them in our social and cultural influences that affect our lives. 
Creating an artwork is also an aesthetic experience as it involves perception, cognition, imagination, emotion, and discovery. Creation of artworks and viewing of artworks work as instruments of aesthetic experience. A curriculum designed to teach aesthetic experience should incorporate both art viewing and art making. While perceiving an artwork there is an interaction between the viewer and the artwork and it leads to aesthetic experience whereas interaction between artist and the medium leads to aesthetic experience during the creation of an artwork.

Aestheticians argue that aesthetic experience helps in harmonizing imagination, physicality, and thinking-in-action. Aesthetic experience integrates mind, body, and emotion. Aesthetic experience can induce personal growth and it is intrinsically satisfying. It is interactive, engages viewers with people, objects, and ideas. For achieving optimal development of children, aesthetic experience must be incorporated into education which will foster better teaching and learning.

\section{REFERENCES}

[1] Apter M.J. (1984). Reversal theory cognitive synergy and the arts. Cognitive processes in the perception of art.In Markovi'c, S. (2012). Components of aesthetic experience: aesthetic fascination, aesthetic appraisal, and aesthetic emotion. i-Perception, 3, pp $1-17$. Retrieved from dx.doi.org/10.1068/i0450aap.

[2] Augustin, M. D., Defranceschi, B., Fuchs, H.K., et al. (2011). The neural time course of art perception: An ERP study on the processing of style versus content in art. In Leder, H., Gerger, G., \& Brieber, D. (2015). Aesthetic appreciation: convergence from experimental aesthetics and physiology. Retrieved from https://www.researchgate.net/publication/282877244.

[3] Beardsley, M. C. (1958/1966). Aesthetics from classical Greece to the present. In Cupchik, G. C., Vartanian, O., Crawley, A., \& Mikulis, D. J. (2009). Viewing artworks: Contributions of cognitive control and perceptual facilitation to aesthetic experience. Brain \& Cognition, 70, 84-91. doi: 10.1016/j.bandc.2009.01.00.

[4] Black, M.G. (2000). Teaching for the aesthetic experience. Dissertation. Lesley University. Retrieved from http://www.archive.org/details/teachingforaesthOOmarg.

[5] Cela-Conde, C. J., Marty, G., Maestú, F., et.al. (2004). Activation of the prefrontal cortex in the human visual aesthetic perception, Proceedings of the National Academy of Sciences, USA 101, 6321-6325.doi:10.1073/pnas.0401427101

[6] Chen, C.H. (2001). Aesthetic thinking of young children and adolescents. Visual Arts Research, 27(2): 47-56. Retrieved from http://www.jstor.org/stable/20716036.

[7] Cole, L. (1994). Activating aesthetic dialogue with young children: A multi-response approach. In Danko-McGhee, K. (2006). Nurturing Aesthetic Awareness in Young Children: Developmentally Appropriate Art Viewing Experiences. Art Education, 59(3): 20-24, 33-35. Retrieved from http://www.jstor.org/stable/27696143.

[8] Csikszentmihalyi, M. (1975). Beyond boredom and anxiety. San Francisco CA: Jossey-Bass. Retrieved from http://psy2.ucsd.edu/ nchristenfeld/Happiness_Readings_files/Class\%207\%20\%20Csikszentmihalyi\%201975.pdf.

[9] Csikszentmihalyi, M. (1990). Flow: The Psychology of Optimal Experience. New York: Harper Collins and Row. Retrieved from https://www.researchgate.net/publication/224927532_Flow_The_Psychology_of_Optimal_Experienc e/link/55ad6c2f08aed614b097b39e/download.

[10] Csikszentmihalyi, M. (2000). Notes on Art Museum Experiences. In Lankford, E.L. (2002). Aesthetic Experience in Constructivist Museums. The Journal of Aesthetic Education, 36(2): 140153. Retrieved from http://www.jstor.org/stable/3333763

[11] Cupchik, G.C., \& Laszlo, J. (1992). Emerging visions of the aesthetic process. Psychology, semiology and philosophy. Retrieved from https://www.researchgate.net/publication/270335136_Emerging_Visions_of_the_Aesthetic_Process_ Psychology_Semiology_and_Philosophy.

[12] Cupchik, G. C., \& Winston, A. C. (1996). Confluence and divergence in empirical aesthetics philosophy and mainstream psychology. In E. C. Carterette and M. P. Friedman (Eds.), Handbook of perception \& cognition, cognitive ecology (pp. 62-85). San Diego, CA: Academic Press. 
[13] Cupchik, G. C., Vartanian, O., Crawley, A., \& Mikulis, D. J. (2009). Viewing artworks: Contributions of cognitive control and perceptual facilitation to aesthetic experience. Brain \& Cognition, 70, 84-91. doi: 10.1016/j.bandc.2009.01.003.

[14] Danko-McGhee, K. (2006). Nurturing Aesthetic Awareness in Young Children: Developmentally Appropriate Art Viewing Experiences. Art Education, 59(3): 20-24, 33-35. Retrieved from http://www.jstor.org/stable/27696143.

[15] Dewey, J. (1934). Art as experience. New York: Minton, Balch.

[16] Earl of Shaftesbury, A. (1711/1964). Characteristics of men, manners, opinions, and times (Vol. 1). In Cupchik, G. C., Vartanian, O., Crawley, A., \& Mikulis, D. J. (2009). Viewing artworks: Contributions of cognitive control and perceptual facilitation to aesthetic experience. Brain \& Cognition, 70, 84-91. doi: 10.1016/j.bandc.2009.01.003.

[17] Efland, A.D. (2004). The entwined nature of the aesthetic: A discourse on visual culture. Studies in Art Education, 45(3); 234-251. Retrieved from http://www.jstor.org/stable/1320971.

[18] Eglinton, K. (2003). Art in the early years. London: Routledge Falmer.

[19] Eisner, E.W. (2002). The arts and the creation of mind. New Haven, CT: Yale University Press.

[20] Feldman, D.H. (1994). Beyond universals in cognitive development. In Chen, C.H. (2001). Aesthetic Thinking of Young Children and Adolescents. Visual Arts Research, 27(2): 47-56. Retrieved from http://www.jstor.org/stable/20716036.

[21] Goodman, N. (1984). Of mind and other matters. Cambridge, MA: Harvard University Press

[22] Heid, A. (2008). Care, Sociocultural Practice, and the Aesthetic Experience in the Art Classroom. Visual Arts Research, 34(1): 87-98. Retrieved from http://www.jstor.org/stable/20715464.

[23] Hutcheson, F. (1725). An inquiry into the original of our ideas of beauty and virtue. London: D. Midwinter and Others. Retrieved from https://ia802608.us.archive.org/6/items/aninquiryintothe00hutcuoft/aninquiryintothe00hutcuoft.pdf.

[24] Jacobsen, T., Schubotz, R., Hofel, L., \&Cramon, D.Y. (2006). Brain correlates of aesthetic judgment of beauty. NeuroImage, 29: 276 - 285. doi: 10.1016/j.neuroimage.2005.07.010.

[25] Kant, I. (1790/1914). Critique of judgment (J. H. Bernard, Trans.). London: MacMillan.

[26] Kawabata, H., \& Zeki, S. (2004). Neural correlates of beauty. Journal of Neurophysiology, 91, 4, 1699- 1705. Retrieved from https://doi.org/10.1152/jn.00696.2003.

[27] Kerdeman, D (2005). Aesthetic Experience and Education: Themes and Questions. The Journal of Aesthetic Education, 39(2): 88-96. Retrieved from http://www.jstor.org/stable/3527408.

[28] Kuchinke, L., Trapp, S., Jacobs, A.M., et al. (2009). Pupillary responses in art appreciation: Effects of aesthetic emotions. Psychology of Aesthetics Creativity and the Arts, 3, 156-63. doi: $10.1037 / \mathrm{a} 0014464$.

[29] Lankford, E.L. (2002). Aesthetic Experience in Constructivist Museums. The Journal of Aesthetic Education, 36(2): 140-153. Retrieved from http://www.jstor.org/stable/3333763.

[30] Leder, H., Belke, B., Oeberst, A., \& Augustin, D. (2004). A model of aesthetic appreciation and aesthetic judgments. British Journal of Psychology 95,489-508. doi:10.1348/0007126042369811.

[31] Leder, H., Gerger, G., \& Brieber, D. (2015). Aesthetic appreciation: convergence from experimental aesthetics and physiology. Retrieved from https://www.researchgate.net/publication/282877244.

[32] Markovi'c, S. (2012). Components of aesthetic experience: aesthetic fascination, aesthetic appraisal, and aesthetic emotion. i-Perception, 3, 1 - 17. Retrieved from dx.doi.org/10.1068/i0450aap.

[33] Maslow, A. (1968). Toward a psychology of being. New York: Van Nostrand.

[34] Ognjenovi'c, P. (1997). Psihološka teorija umetnosti [Psychological theory of art]. In Markovi'c, S. (2012). Components of aesthetic experience: aesthetic fascination, aesthetic appraisal, and aesthetic emotion. i-Perception, 3, 1 - 17. Retrieved from dx.doi.org/10.1068/i0450aap.

[35] Parsons, M. J. (1987). How we understand art: A cognitive developmental account of aesthetic experience. Cambridge: Cambridge University Press.

[36] Parsons, M. (2002). Aesthetic Experience and the Construction of Meanings. The Journal of Aesthetic Education, 36(2): 24-37. Retrieved from http://www.jstor.org/stable/3333755.

[37] Savva, A. (2003). Young pupil's responses to adult works of art. Contemporary Issues in Early Childhood, 4(3): 300-313. doi: 10.2304/ciec.2003.4.3.6.

[38] Savva, A., \& Trimis, E. (2005). Responses of young children to contemporary art exhibits: The role of artistic experiences. International Journal of the Education and the Arts, 6(13): 1-22. Retrieved from http://ijea.asu.edu/v6n13/ 
International Journal of Education (IJE) Vol.8, No.4, December 2020

[39] Scherer, K.R. (2005). What are emotions? And how can they be measured? Social Science Information, 44, 695-729. doi: 10.1177/0539018405058216.

[40] Schirrmacher, R. (2002). Art and creative development for young children. In Danko-McGhee, K. (2006). Nurturing Aesthetic Awareness in Young Children: Developmentally Appropriate Art Viewing Experiences. Art Education, 59(3): 20-24, 33-35. Retrieved from http://www.jstor.org/stable/27696143.

[41] Schopenhauer, A. (1818/1969). The world as will and representation (Vol. 1) (E. J. Payne, Trans.). New York: Dover. Retrieved from https://www.gutenberg.org/files/38427/38427-pdf.pdf.

[42] Smith, R. A. (1986/1987). Excellence in art education: Ideas and initiatives. In Efland, A.D. (2004). The entwined nature of the aesthetic: A discourse on visual culture. Studies in Art Education, 45(3); 234-251. Retrieved from http://www.jstor.org/stable/1320971.

[43] Smith, R.A. (1991). Art Education: A Critical Necessity. Urbana: University of Illinois Press.

[44] Swami, V. (2013). Context matters: Investigating the impact of contextual information on aesthetic appreciation of paintings by Max Ernst and Pablo Picasso. Psychology of Aesthetics, Creativity, and the Arts 7, 285-95. doi:10.1037/a0030965.

[45] Tellegan, A., \& Atkinson, G. (1974). Openness to absorption and self-altering experiences: A trait related to hypnotic susceptibility. Journal of Abnormal Psychology, 83,268-277 doi:10.1037/h0036681.

[46] Vartanian, O., \& Goel, V. (2004). Neuroanatomical correlates of aesthetic preference for paintings. Neuroreport, 15, 893-897. doi: 10.1097/01.wnr.0000118723. 38067.d6.

[47] Vartanian, O., \& Nadal, M. (2007). A biological approach to a model of aesthetic experience. In L. Dorfman, C. Martindale, \& V. Petrov (Eds.), Aesthetics and innovation (pp. 429-444). Newcastle, UK: Cambridge Scholars Publishing. Retrieved from https://neuroaestheticsnet.files.wordpress.com/2012/10/vartaniannadal3.pdf. 